This paper presents a trajectory built for the accomplishment of a dialogical research/analysis focusing a visual art textbook. With the intention of raising questions about the forms through which knowledge (text and image) is presented, organized and sequenced in this educational resource, this study looks at perceptions, interpretations and reactions of students to the textbook. The textbook, in this context, is understood as a cultural device that delimits and transfigures our relations with the symbolic and cultural world. After a brief discussion about the concept and characteristics of the textbook we present and discuss some procedures developed in this research process aiming to describe and analyze student's interactions with the textbook

Keywords: Textbook, visual arts, dialogical research. 


\title{
Como e porque investigar o livro didático para o ensino de artes visuais
}

\author{
Irene \\ TOURINHO
}

Gisele

COSTA

Este trabalho apresenta a trajetória construída para a realização de uma análise dialogada/pesquisa cujo objeto é o livro didático (LD) de artes visuais. Com o intuito de levantar questões sobre as formas como o conhecimento (texto e imagem) em arte é apresentado, organizado e seqüenciado neste suporte educacional, este estudo se debruça sobre percepções, interpretações e reações dos alunos ao livro didático. O livro didático é, assim, entendido como um artefato cultural que delimita e transfigura nossas relações com o mundo simbólico e cultural. Após breve discussão sobre questões conceituais e características do livro didático, apresentamos e discutimos alguns procedimentos desenvolvidos no processo desta pesquisa visando descrever e analisar as interações dos alunos com o LD.

Palavras-chave: Livro didático, artes visuais, pesquisa dialogada. 


\section{Aproximações...}

No início deste trabalho, considerávamos que a pouca intimidade entre objeto de pesquisa e pesquisadoras devia-se ao curto tempo de experiência com certos temas de investigação. Entretanto, aos poucos fomos nos identificando com Flusser e sentindo na pele o valor da sua opinião de que "a dúvida, aliada à curiosidade, é o berço da pesquisa, portanto de todo conhecimento sistemático" (1999, p. 17). Passado um ano, percebemos que outras questões vão surgindo na tentativa de esclarecer dúvidas iniciais, e que este processo de acumulação de dúvidas é um caminho sem volta.

Lidar com esta falta de inteireza do conhecimento é assunto que Kincheloe e Berry (2007) tratam em detalhe. Eles nos falam do perspectivismo, base dos pesquisadores bricoleurs que, "ao contrário do empirismo radical do positivismo (...) nega que algo possa ser conhecido de forma completa e final" ( $p$. 112). O que primeiro instigou nossa atenção para este trabalho foi o recorrente 'boato' da aposentadoria do livro didático em função de novas tecnologias. Tal boato nos instigou porque era um falso alarme, pois não aconteceu.

Pesquisas realizadas nas últimas décadas como as de Coutinho e Freire (2007), Choppin (2002), Ferraz e Siqueira (1987), Martins (2007), Apple (1986) e Tonini (2007) reforçam a quase onipresença do uso dos livros didáticos em várias partes do mundo como, por exemplo, Estados Unidos, Canadá, Japão, Brasil, etc. Como professoras e pesquisadoras, nossa curiosidade direcionou-se ao livro didático (LD) voltado para o ensino das artes visuais, sobre os quais carecem estudos e avaliação.

O primeiro passo desta trajetória se concretizou em uma pesquisa bibliográfica sobre o LD buscando entendê-lo como artefato cultural inserido no contexto educativo, dotado de "uma história que não está desvinculada da própria história do ensino escolar, do aperfeiçoamento das tecnologias de produção gráfica e dos padrões mais gerais de comunicação na sociedade" (MARTINS, 2007, p.7). A história do ensino e da disciplina artes visuais, as transformações tecnológicas e as novas formas de comunicação são, como aponta o autor, pontos que se entrelaçam no exame de LDs. Durante o levantamento 
bibliográfico, ainda em curso, encontramos um grande número de pesquisas que tinham o LD como tema, porém, isso não acontece em relação aos LDs para o ensino de arte.

Olhando o LD como objeto de investigação, tornou-se necessário aproximarmo-nos de uma 'voz oficial' que falasse sobre o tema. Esta voz foi encontrada no Guia de Livros Didáticos do Ministério da Educação (2004) na afirmação de que "o livro didático brasileiro, ainda hoje, é uma das principais formas de documentação e consulta empregadas por professores e alunos" (p.10) e que "é fundamental dispor de um livro didático diversificado e flexível, sensível à variação das formas de organização escolar e dos projetos pedagógicos, assim como às diferentes expectativas e interesses sociais e regionais" (p.10). O citado Guia não faz recomendações de LDs de artes visuais, fato que não implica na sua não-utilização, publicação e divulgação.

A adoção de LD para o ensino de arte é tema polêmico. Ferraz e Siqueira (1987), em pesquisa realizada no estado de São Paulo, levantaram o debate do uso/adoção ou não dos livros didáticos para o ensino de arte e concluíram que, tendo em vista os propósitos deste ensino, "ela [a arte] opõe-se frontalmente ao livro didático, que é estático, geralmente reducionista, cerceador da liberdade" (p.12). Contudo, através da maioria dos questionários respondidos naquela pesquisa, as autoras confirmam que é amplo o uso dos LDs. Em função disso, surgem questionamentos relevantes para a discussão de temas específicos do ensino de arte, tais como refletir sobre as formas que fazem o LD 'reducionista' (o que ele seleciona e reduz?); discutir como eles cerceiam a liberdade e, também, como, quando e porque eles apóiam o trabalho dos professores.

Neste processo de aproximação com o LD, deparamo-nos com alguns conceitos. Para Apple (1986), os LDs "significam construções particulares da realidade, modos peculiares de selecionar e organizar um vasto universo de conhecimento possível" (p.77) configurando, assim, representações de arte na sociedade, na cultura, na educação e no campo das identidades. Também deve ser visto como um produto editorial, vinculado ao mercado, selecionado segundo a perspectiva do lucro. As- 
sim, "por trás da mercadoria, o livro, existe na verdade, um completo conjunto de relações humanas" (p. 87) que envolvem quem o utiliza, alunos e professores, assim como profissionais que trabalham nos processos de concepção, produção, distribuição e divulgação desses materiais.

Coutinho e Freire (2007) afirmam que o LD é um recurso "auxiliado pela adoção, em paralelo, de todo um conjunto de artefatos comunicacionais que outrora não era evidenciado no ambiente escolar: jornais, revistas, quadrinhos, rótulos, quadros e tabelas, placas, cartazes e peças publicitárias" (p.248). Para Tonini (2007), em sintonia com a posição de Apple (1986), o LD "é produtor de uma forma de pensar e fazer" e transmite o conhecimento 'verdadeiro' que assegura o desenvolvimento de propostas de trabalho e garante a circulação de conteúdos necessários e corretos para a aprendizagem. Esta posição de Tonini coloca em pauta uma série de questões que dizem respeito ao que seria considerado conhecimento verdadeiro, que segurança e garantia de aprendizagem podemos esperar de um recurso pedagógico como este e, também, que conteúdos poderiam ser vistos como necessários e corretos. São questões que exigem uma investigação criteriosa, buscando examinar os LDs tanto em relação ao que e como apresentam, mas, ainda, tentando refletir sobre o conteúdo dos LD na perspectiva de professores e, também, de alunos.

Entretanto, as formas de aproximação com o LD passam, de maneira imprescindível, pela discussão do conceito atrelado a este recurso. Chopin (2002) considera a "definição 'livro didático' complicada pelo conceito pré-estabelecido pelo senso comum e familiaridade no contexto escolar" (p.21). Para ele, o LD é "uma reconstrução com o objetivo de educar 'moralmente' novas gerações, silenciando os conflitos sociais, os atos delituosos ou a violência cotidiana, independentemente da disciplina em questão" (p.32).

Esta preocupação conceitual se estende para outras caracterizações que também vêm sendo abordadas por pesquisadores brasileiros. Machado (2007), por exemplo, reflete sobre quatro pontos centrais no processo de produção e análise do livro didático: qualidade, quantidade, custo e atualização. Pri- 
meiro, ele reconhece que existem livros didáticos bons e ruins. O conteúdo faz parte desta avaliação tanto quanto sua organização, a linguagem, sua forma e ritmo de consumo, além da articulação de determinados conhecimentos pelo professor, mediador do conhecimento e da aprendizagem. O autor também considera importante a questão da quantidade de livros à disposição dos alunos, sua forma de utilização, descarte e disponibilidade em espaços como bibliotecas e salas de estudo nas escolas.

Para nos inteirar dos custos dos LD, um dos pontos que Machado (2007) destaca, fizemos um levantamento em três grandes editoras que têm lojas em Goiânia: FTD, Ática e Saraiva. Em 2007 e 2008, os LDs para o ensino de arte custam entre trinta e cinco e sessenta reais, preço bastante elevado para a maioria dos estudantes do país. Mesmo com a "diminuição nos custos da produção editorial, eliminando etapas como a datilografia dos originais e (...) simplificando tarefas relativas à diagramação ou à composição" (p.4) proporcionadas pelas novas tecnologias, o preço final dos LD permanece muito alto. Este custo fica ainda mais elevado se considerarmos que grande parte deles é descartável, podendo ser usado apenas uma vez.

A atualização ou desatualização, último aspecto discutido por Machado, refere-se à apresentação dos conteúdos e diz respeito "à concepção de conhecimento que implicitamente veiculam, em todas as áreas", mais do que "às informações tópicas nos diversos temas abordados" (p.6). Nos casos dos LDs de arte que examinamos inicialmente, visando conhecer algumas de suas características, evidenciamos uma ausência de posicionamento dos autores sobre como pensam e compreendem o conhecimento em arte. Uma discussão detalhada a este respeito não cabe nos limites deste texto e deverá ser objeto de outro trabalho.

Não temos conhecimento de que os aspectos discutidos por Machado tenham sido investigados em relação ao LD de arte, condição que deixa em aberto uma via de pesquisa a ser trilhada e que reforça a necessidade de iniciar uma jornada nesta direção. A investigação que propomos enfatiza a organização, estrutura e seqüência dos conteúdos; os tipos de enunciados e 
propostas apresentados pelo livro, assim como sua linguagem. Um interesse particular se foca na imagem, elemento que deverá ser examinado pela qualidade, quantidade, temas, origens, artistas, estilos, cenários, suportes e técnicas privilegiados.

O eixo desta pesquisa é, então, formado pela imagem e pelo texto, pelos saberes que selecionam, criam, veiculam, 'naturalizam' e transformam sobre arte. Dentre os inúmeros questionamentos com os quais nos deparamos, dois se impuseram como principais, direcionando nossa caminhada: como o livro didático apresenta e organiza o conhecimento (texto e imagem) em arte? Como os alunos percebem, interpretam e reagem aos conteúdos do livro didático?

Assim, a pesquisa se concentra em dois focos. Um deles levanta e comenta as imagens e textos encontrados no LD, analisando seus temas, enunciados e linguagem, observando aspectos gráficos e formais, e, principalmente a relação entre conteúdos e propostas, sua organização e continuidade. O outro foco dirige sua atenção para os alunos colaboradores que fazem parte do grupo focal da pesquisa. A preocupação central é com as descrições, críticas e apreciações a respeito do LD e seus conteúdos, ou seja, as conjecturas, observações e vínculos que os alunos estabelecem com o objeto. Nos ativemos, ainda, à análise das possibilidades de reconstrução e propostas sugeridas pelos alunos durante a investigação.

\section{Trabalho de campo: orientações metodológicas}

Em função das características desta investigação trata-se de uma pesquisa de caráter qualitativo. O termo 'pesquisa qualitativa' constitui um conceito muito amplo que faz referência a diversas perspectivas epistemológicas e teóricas, incluindo numerosos métodos e estratégias de investigação não excludentes entre si. Esteban (2003) ressalta que a pesquisa qualitativa é "uma atividade sistemática orientada à compreensão em profundidade de fenômenos educativos e sociais, à transformação de práticas e cenários sócio-educativos, à tomada de decisões". Segundo o autor, tal metodologia "também faz uma descoberta e desenvolvimento de um corpo organizado de conhecimen- 
tos" (p.123).

Os elementos empíricos da investigação são "recolhidos em situação e complementados pela informação que se obtém através do contato direto" (BOGDAN \& BLIKEN, 1994, p.48). Os autores comentam que, neste tipo de pesquisa, "o comportamento humano é significativamente influenciado pelo contexto em que ocorre" (p.48). Outra característica da pesquisa qualitativa é sua forma descritiva, incluindo "transcrições de entrevistas, notas de campo, fotografias, vídeos, documentos pessoais, memorandos e outros registros oficiais" (p.48). O processo da pesquisa qualitativa é o núcleo da investigação que preocupa-se em como se constroem sentidos sobre conceitos e definições encontrados. Não existe a intenção de confirmar e/ ou comprovar hipóteses previamente construídas, e, por isso, a pesquisa é indutiva e ganha forma ao longo do recolhimento das informações e análise das mesmas. Durante a condução da pesquisa, o diálogo entre pesquisador e sujeitos é sempre uma constante e tem o objetivo de desvendar os sentidos que atribuímos à nossas ações, interações e formas de compreensão.

Traçar um plano para a pesquisa qualitativa é muito difícil porque depende dos sujeitos, do ambiente, da observação, da narrativa realizada depois da reunião de informações, peças fundamentais para um planejamento mais detalhado. Porém, é possível fazer um "plano flexível". Depois de um primeiro investimento na pesquisa bibliográfica - que acompanha o desenvolvimento do estudo - algumas escolhas são necessárias. Definir quais ou qual LD seria o foco foi escolha fundamental, facilitada pelas referências e impacto (comercial) dos LDs. A ampla publicidade em relação a materiais didáticos e a polêmica que o LD gera facilitou esta escolha.

Os LDs de artes visuais mais encontrados pertencem às cinco maiores editoras, exatamente aquelas citadas no Guia Nacional dos Livros Didáticos: FTD, Saraiva, Scipione, Ática e Brasil. Além da divulgação e comercialização, outro juízo de seleção do material para a pesquisa foi o número de impressões e edições de um mesmo título. Além desses, utilizamos o critério de disponibilidade em bibliotecas e espaços públicos tanto municipais quanto estaduais, verificando a disponibilidade também 
nas escolas nas quais os LDs não são 'oficialmente' adotados.

A faixa etária do grupo de estudantes colaboradores desta pesquisa varia de treze a dezesseis anos. São alunos que cursam a $7^{a}$ e $8^{a}$ séries e/ou $8^{\circ}$ e $9^{\circ}$ anos do ensino fundamental. O motivo desta escolha foi privilegiar uma maioria de alunos que, neste último ciclo de ensino, tem sua última oportunidade de experimentar práticas artísticas já que, geralmente, o foco dos LDs do ensino médio passa a ser a história da arte. Outra razão para a escolha deste grupo se deu pela motivação que esses alunos demonstravam na expectativa de passar para o ensino médio. Esta condição beneficiava a possibilidade de dialogar com, propostas, críticas, expectativas, preferências e visões sobre o LD. Nesse sentido, entendíamos que os anos de escolarização já vividos colocariam tais alunos em situação de maior liberdade para confrontar-se com os referidos materiais.

Um grupo focal, realizado na própria escola durante as aulas de artes visuais, e sob nossa orientação e mediação, é a principal atividade de pesquisa e compreende a análise do LD como parte do planejamento da disciplina, cuja responsável é a professora Rogéria Eller. Os encontros começaram em setembro de 2007 e foram semanais, estendendo-se por um período aproximado de quinze semanas. O grupo iniciou com a participação de vinte alunos do turno noturno. Mesmo que este número tenha diminuído um pouco, situação comum nas escolas e em trabalhos empíricos desta natureza, nosso objetivo de "explorar o espectro de opiniões, as diferentes representações sobre o assunto em questão" (GASKELL, 2002, p.68) está preservado.

Fazem parte do plano de investigação alguns procedimentos metodológicos voltados para a imagem que se caracterizam com os mixing methods propostos por Gillian Rose (2001). A autora apresenta alguns métodos de 'interpretar' as imagens de acordo com formas de produção, aspectos da própria imagem e a audiência à mesma, assim como as características formais da imagem como sua composição, a tecnologia usada para produzi-la e apresentá-la e também as relações sociais que derivam e se originam dela (p.17-28). A análise em processo é feita a partir de vários procedimentos concomitantes e não 
apenas baseada em uma abordagem. Assim procuramos evitar a possibilidade de ter a complexidade de uma imagem reduzida a "poucas dimensões abstratas" o que seria prejudicial à pesquisa em questão (PENN, 2002, p.335). Michael J. Parsons (1987), contribui para uma futura articulação dos resultados das interações em sala de aula quando expõe sua idéia de que a arte é

diferente de ciência, moralidade, religião, como parte da distinção das mentes humanas por suas próprias preocupações e conceitos característicos. (...) Nós geralmente olhamos para a arte pela beleza, expressão, estilo e qualidades formais. (...) não é apenas um conjunto de coisas bonitas, é uma maneira de articular nossa vida interior (p. 13).

Nessa afirmação, Parsons faz um alerta para as visões da arte veiculadas socialmente, não se restringindo apenas ao âmbito escolar. Tal constatação permite que uma pesquisa sobre um recurso pedagógico como os livros didáticos nos leve a enfrentar questões que também nos inquietam, e já surgiram na forma de comentários no grupo, como a ausência de referências de arte brasileira na formação básica, a inutilidade dos conhecimentos artísticos para a sobrevivência e a crítica sobre a banalização da arte na contemporaneidade que, para os alunos, significa dizer que tudo pode ser arte.

Este trabalho, além de abordar uma situação de pesquisa, reflete sobre metodologias para sua realização e pensa a tentativa de traçar um plano para realizá-la. Nesta tarefa, sobressaem dificuldades e uma delas diz respeito exatamente à construção de uma 'obra'. Corazza (2002) serve de estímulo para momentos angustiantes quando nos diz: "coragem companheira/o. Não dá para desejar que o mundo seja leve, pois inventaste de ser intelectual" (p.110).

\section{Referências}

APPLE, M. Teachers \& Texts. A Political Economy of Class \& Gender Relations in Education. New York: Routledge, 1986.

BOGDAN, Robert; BIKLEN, Sari. Investigao qualitativa em educao: uma introdução à teoria e aos métodos. Porto: Porto Editora, 1994. 
CHOPIN, A. História dos livros e edições didáticas: sobre o estado da arte. In: Revista Paedagogica Histrica. V.38, N.1, 2002, p.21-49.

CORAZZA, Sandra M. Labirintos da pesquisa, diante dos ferrolhos. In: Caminhos investigativos l: novos olhares na pesquisa em educação. Marisa V. Costa (org.). Rio de Janeiro: DP\&A, 2002, p. 105-131.

CORAZZA, Sandra M. Labirintos da pesquisa, diante dos ferrolhos. In.: Caminhos investigativos III: novos olhares da pesquisa em educação. Marisa V. Costa(org.). Rio de Janeiro: DP\&A, 2002, p.105-131.

COUTINHO, S. e FREIRE, V. Design para educação: uma avaliação do uso da imagem nos livros infantis de língua portuguesa. In: Arte: Limites e Contaminações. V.2. Cleomar Rocha (org.). Anais do XV Encontro Nacional da ANPAP. Salvador: UNIFACS, 2007, p.245-254.

FLUSSER, Vilém. A dvida. Rio de Janeiro: Relume Dumará, 1999.

GASKELL, George e BAUER, Martin W. Pesquisa Qualitativa com texto, imagem e som: um manual prático. Petrópolis, RJ, 2002, p. 64-113.

KINCHELOE, J. e BERRY, K. Pesquisa em Educao - Conceituando a bricolagem. Porto Alegre: Artmed, 2007.

PARSONS, Michael J. How we understand art: a cognitive developmental account of aesthetic experience.

PENN, Gemma. Análise semiótica de imagens paradas. In.: Pesquisa Qualitativa com texto, imagem e som: um manual prático. Petrópolis, RJ, 2002, p. 319-342..

ROSE, Gillian. Visual methodologies. Londres: SAGE Publications, 2001.

TONINI, I. Imagens nos livros didáticos de Geografia: Seus ensinamentos, sua pedagogia. Www.mercator.ufc.br/revistamercator, acessado em 28/03/2007

Guia do livro didtico. Brasília: Ministério da Educação, 2004. 


\section{IRENE TOURINHO}

Professora Titular da Faculdade de Artes Visuais da Universidade Federal de Goiás, Pós-Doutora pela Universidade de Barcelona (Espanha), Doutora pela Universidade de Wisconsin-Madison, (EUA) e Mestre pela Universidade de lowa (EUA). Foi professora visitante na Faculdade de Belas Artes da Universidade de Barcelona. Email: irenetourinho@yahoo.es

\section{GISELE COSTA}

Professora e Coordenadora da pós-graduação em Comunicação e Marketing da Faculdade Araguaia, com Aperfeiçoamento em Patrimônio Cultural e Museologia pela PUC-MG. Mestre em Cultura Visual pela FAV-UFG, foi professora de Artes Visuais na Rede Pública Estadual de Goiás e atua como professora orientadora no curso de Licenciatura em Artes Visuais da 